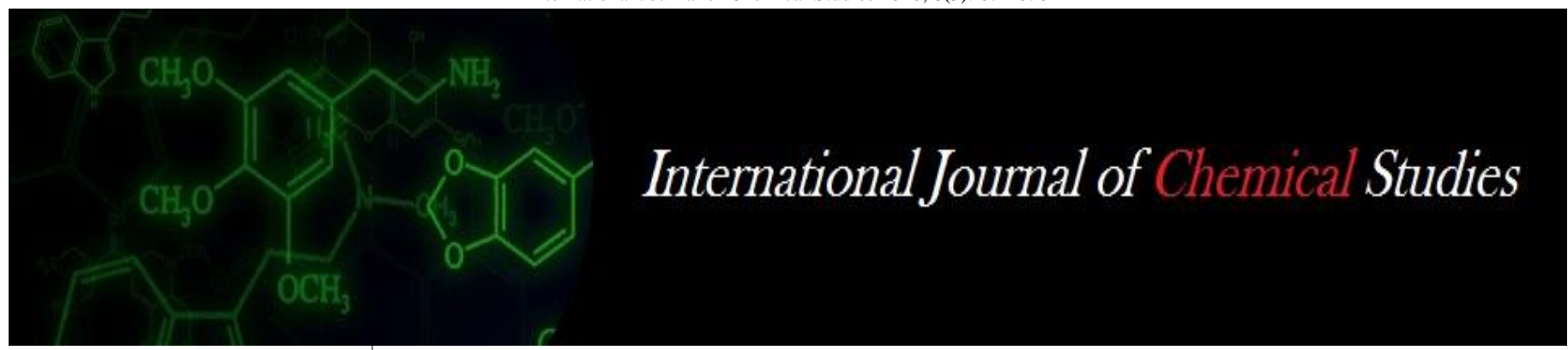

P-ISSN: 2349-8528

E-ISSN: 2321-4902

www.chemijournal.com

IJCS 2020; 8(5): 674-676

(C) 2020 IJCS

Received: 04-07-2020

Accepted: 06-08-2020

Jyoti Ranjan Rath

Research Scholar, Dept. of Agril.

Economics, Visva Bharati

University, West Bengal, India

MK Ghosal

Professor, Department of Farm

Machinery and Power, Odisha

University of Agriculture and

Technology, Bhubaneswar,

Odisha, India
Corresponding Author: Jyoti Ranjan Rath

Research Scholar, Dept. of Agril.

Economics, Visva Bharati

University, West Bengal, India

\section{Studies on environmental control of greenhouse for crop production}

\section{Jyoti Ranjan Rath and MK Ghosal}

DOI: https://doi.org/10.22271/chemi.2020.v8.i5j.10377

\begin{abstract}
The design of a greenhouse mainly depends on the type of plants to be grown in the greenhouse, the light and heat requirements of plants, season of crop cultivation, desired degree of automation, topography, climate and mode of business. Environmental control can be achieved if greenhouse is designed accordingly by considering the optimum responses of the crop. Since the natural environment and the input availability may not be optimum as a place for proper growth, the controlled environment greenhouse is the right approach for maximising productivity. This paper elucidates the number of structural and operational design as well as the optimum level of environmental parameters for enhancing productivity in an energy efficient and economically viable solar greenhouse.
\end{abstract}

Keywords: Environmental control, greenhouse, crop production

\section{Introduction}

In the present scenario of increasing demand of vegetable and drastic shrinkage of land holdings, greenhouse cultivation is the best alternative for using land and other resources efficiently. The favourable environment in the greenhouse not only enhances the productivity but also creates a good market of fresh vegetable during off-season by providing maximum returns to the growers. This greenhouse technology has tremendous scope in horticultural sector, especially in production of hybrid seeds, vegetables, ornamental plants, medicinal plants and flowers. This technology is not new but has been prevailing since one and half centuries in various parts of the world. In India, this concept was adopted only during 1980's and was confined in research activities. However, in recent years, greenhouse cultivation came into picture for globalisation of international market and tremendous boost of agricultural produce and at present the area under greenhouse in India has been increased to 10, 000 ha (Anon 2017) ${ }^{[1]}$. Still there is more scope of covering the area under greenhouse cultivation of vegetables and flowers due to higher yield as compared to open filed cultivation, off-season production and good quality production throughout the year.

Necessary sunlight and heat are the key requirements in the greenhouse for photosynthesis, growth and production. Although each plant type requires a little different type of environment for higher production but basically the desirable needs are moderate temperature, light, carbondioxide, mineral nutrients, air movement and water. Many researchers have pointed out that low temperature and low radiation retard the growth of plants and fruit size because plant temperature provides a platform to basic physiological processes common to all plants (Shamshiri et al. 2014, Montero et al. 2017) ${ }^{[11,15]}$. These include photosynthesis, respiration, translocation, ion uptake, transpiration, pigment formation, reproduction, bulbing, elongation and many other factors. Temperature influence all these processes in various ways and to different degree (Zhang et al. 2015) ${ }^{[12]}$. Also the heat is to be stored for use at night and for cloudy days the solar energy is collected and stored in a variety of ways and therefore the greenhouses differ in their designs. Moreover, the solar collection and storage system depend on many factors like climate, greenhouse size, plant type, orientation, economics and whether a new greenhouse is to be planned or existing one is to be modified (Jain and Tiwari 2002) ${ }^{[13]}$. Recently many designs have been developed and perfect techniques have been evolved to make the greenhouse technology economical and energy efficient. The technologies regarding the classification of greenhouse, constituents of controlled environment, thermal analysis and 
design are described in this paper with a view to make the greenhouse profitable and techno-economically feasible as compared to traditional open field cultivation.

\section{Working Principle}

Agriculture is basically an energy conversion process. It is both a producer and consumer of energy. This process involves the conversion of solar energy into bio-mass by way of photosynthesis. According to Dalrymple (1973) [2], greenhouse is a farmed or inflated structure covered with transparent or translucent materials. The crop may be grown under the conditions of at least partially controlled environment maintained within the greenhouses which are large enough to allow a person to walk freely inside them for carrying out cultural operations. The greenhouse glazing (glass, plastic, polycarbonate, fibre glass etc.) acts as a selective radiation filter in the sense that visible solar radiation can pass through it but the thermal radiation (infrared radiation) emitted by the objects within the greenhouse cannot escape. This particular effect so called 'greenhouse effect' causes the rise of temperature within the greenhouse. The maximum thermal radiation emitted inside the greenhouse at $20{ }^{0}$ (room temperature) and $200{ }^{\circ} \mathrm{C}$ are of wavelength $10 \mu \mathrm{m}$ and $6 \mu \mathrm{m}$ which cannot pass through the glazing (Seth et al. 2009) ${ }^{[14]}$. At about $500^{\circ} \mathrm{C}$, the glazing becomes partially transparent to the thermal radiation of $4 \mu \mathrm{m}$ emitted by the objects of green house, but in practice this level of high temperature beyond $40{ }^{\circ} \mathrm{C}$ is not possible inside the greenhouse. The closed boundaries of the greenhouse check natural ventilation thus permitting retention of radiant heat within it. The solar energy retained during sunshine hour is re-utilized to maintain higher room temperature and plant temperature during off-sunshine hour.

\section{Methods}

\section{Greenhouse design (orientation and tilt)}

In Northern hemisphere at high latitude stations, sun never shines on the north side, hence most of the glazings in the greenhouse should be provided on the south side. For winter operation, the long axis of the greenhouse should be along east-west direction, admitting more sunlight in winter season (Tiwari and Dhiman 1986). If due to local conditions, it is not possible to orient the greenhouse in east-west direction i.e. facing south then orientation up to $20^{\circ}$ on either side of south direction will not significantly affect the receipt of sunlight. If the slope of the greenhouse roof is between $35^{0}$ to $60^{\circ}$, then even $45^{\circ}$ off-south orientations will change the sunlight availability by only 18 to 20 percent.

\section{Cooling arrangement}

During summer, high solar intensity increases the air temperature inside a greenhouse to a high level. The natural environment becomes unfavourable for crop production. Therefore, thermal cooling of greenhouse is required specially during the peak period of summer. Cooling may be of ventilation (natural or forced convection) and evaporative as well as reduction of solar intensity through shading and misting (Sutar and Tiwari 1996, Baptista et al. 1999) ${ }^{[4,5]}$.

\section{Heating arrangement}

Winter greenhouse requires heating. The passive heating may be due to water storage, rock bed storage, north wall and movable insulation etc. (Singh and Tiwari 2000) ${ }^{[6]}$. The active heating of greenhouse can be done with the help of ground air collector.

\section{Light intensity}

Visible light energy, $\mathrm{CO}_{2}$ and water are used by plants to convert them into carbohydrate and oxygen. This process is known as photosynthesis. For enhancing photosynthesis process, light intensity is highly essential which is available from the visible spectrum $(0.38-0.78 \mu \mathrm{m})$ of solar radiation. The photosynthetic efficiencies under greenhouse cultivation exceed than those of cultivation in open field by three times (Chauhan, 1976) ${ }^{\text {[7] }}$. It is therefore, necessary to ensure the highest solar intensity possible during short day light periods. This can be achieved by cleaning the transparent cover of the greenhouse regularly or by providing refractive surface or by supplement lighting.

\section{Carbon dioxide injection}

Carbon dioxide is the most essential components for promoting photosynthesis process. The crop yield may be increased by 20 to $30 \%$ by maintaining carbon dioxide level up to $1000 \mathrm{ppm}$ (Nelson 1985) ${ }^{[8]}$. The carbon dioxide is supplied to the greenhouse air by burning the biomass with the help of kerosene or by carbon dioxide cylinder, but it should be regularly injected for promoting the plant growth.

\section{Relative humidity}

The relative humidity of air between 50 to $70 \%$ is ideal for plant growth and very high relative humidity (more than 90\%) will provide better environment for pathogenic organism making the plant susceptible to fungal diseases (Bakker 1990) [9]. Low relative humidity is also harmful for plants since it increases the evapo-transpiration rate, which increases the water requirements of plants inside the greenhouse. The relative humidity can be controlled by the process of ventilation which is achieved by means of a fan operated with the help of electricity.

\section{Root media}

Plants need nutrients for growth. Root media, the only source of nutrients is to be prepared properly for greenhouse cultivation (Alhamdan and AI-Helal, 2009) ${ }^{[10]}$. It should meet certain optimum conditions, which are essential for proper functioning of plant roots. In the root media, $30 \%$ of the organic matter should be mixed with soil and sand.

\section{Discussions}

The purpose of greenhouse cultivation is to grow the crops under controlled conditions so as to get maximum potential yield. This may require control of light, temperature, humidity, air and other environmental conditions. While designing the greenhouse, these considerations may have to be looked into, depending upon the location and facility. The green house should be utilised to the fullest extent possible where unfavourable natural ambient conditions prevail. In India, solar energy is abundantly available throughout the year, the greenhouse may not require artificial lighting. However, during summer since the temperature increases very high, the greenhouse should be provided with proper cooling and ventilation arrangements, described earlier. Environment plays a guiding role in determining the growth, development and yield of plants. It influences moisture, temperature, nutrient up-take and insect as well as disease resistance in the plants. In the greenhouse, it is possible to analyse the response of plants to the various environmental factors. Light of desirable quality should be made available in adequate amounts for sufficient duration in order to achieve good crop growth inside the greenhouse. When the natural photoperiods 
are longer than the critical day length of the crop species, the day length can be reduced by covering the plants in the afternoon with the help of an opaque material as described earlier. Greenhouse cultivation leads to 3-4 times higher yield than that of outdoor cultivation, depending upon the greenhouse design, availability of environmental control facilities, cropping system, greenhouse management and crop type. Solar radiation is the most important energy input in greenhouses. It not only provides the energy needed for photosynthesis process but also heats the greenhouse due to greenhouse effect. Solar radiation depends on the angle on incidence, latitude, solar azimuth and solar altitude. Therefore, design of greenhouse varies from place due to variation in climatic parameters. The climate is a major consideration while deciding the location of greenhouse, because is a major consideration while deciding the location of greenhouse, because in greenhouse, cooling/heating cost is a usually the principal production cost followed by labour cost. Climate also dictates what kind of crop is to be produced considering the cost and energy utilization. A greenhouse should be designed to withstand the load of the covering material, intensity of rain, frost and wind velocity. Thus structure becomes location and crop specific and the information presented in the proceeding section give the importance of controlled environment for plant growth. The judicious combination of all micro-climatic factors will definitely enhance the yield of the crop and thereby the growing demand of food, feed and fibre can fulfilled. The greenhouse through environmental control provides higher productivity even under unfavourable land and climatic conditions. The methods explained in the proceeding section for design and environmental control of greenhouse can be applied in the research activities for the production of offseason vegetables and flowers for popularisation of this technology commercially.

\section{Conclusions}

After critically reviewing the design and environmental aspects of a controlled greenhouse, the following conclusions are summarised.

i. In northern hemisphere, the long axis of greenhouse should be oriented in east-west direction for receiving more solar radiation.

ii. North-wall of the greenhouse should be insulated to reduce heat losses from the greenhouse and for better performance, its inside surface may be made reflective. About $20 \%$ heat is retained in the greenhouse by this type of greenhouse design.

iii. About $12 \%$ heat losses can be reduced from the greenhouse environment by using movable insulation over the canopy cover in the night during winter period.

iv. Ground air collector is also an effective way of increasing room air temperature by about $6{ }^{\circ} \mathrm{C}$.

v. The temperature of greenhouse remains $4{ }^{0} \mathrm{C}$ lower than the ambient temperature during summer period by following the evaporative cooling methods.

vi. The ideal temperature ranges for winter crops and summer crops are from $15-20{ }^{0} \mathrm{C}$ and $25-35{ }^{0} \mathrm{C}$ respectively.

vii. Normal light intensity for the growth of plants is 250 $\mathrm{W} / \mathrm{m}^{2}$ which is about one fourth of the maximum light available in a day.

viii. The carbon dioxide concentration should be maintained in the range of 1000-1500 ppm inside the greenhouse during day time for efficient photosynthesis process. ix. The relative humidity between $50-70$ percent inside the greenhouse is ideal for proper growth of the plants

$x$. The yield of the crops inside the greenhouse can be increased 3 times as compared to open field cultivation by maintaining the above environmental parameters.

\section{References}

1. Anon. Hand Book of Agriculture, P - 586, ICAR Publication, New Delhi, 2017.

2. Dalrymple DG. A global review of Greenhouse food production. FAE report No.89, Economic Research service, USDA, Washington EC, 1973

3. Tiwari GN, Dhiman NK. Optimization of a winter greenhouse for Leh condition. Energy Conversion and Management, 1986; 26:71.

4. Sutar RF, Tiwari GN. Reduction of temperature inside a greenhouse. Energy. 1996; 21:61-65.

5. Baptista FJ, Bailey BJ, Randal JM, menses JF. Greenhouse ventilation rate; theory and measurement. J. of agril. Engg. Research, 1999; 72:363-374.

6. Singh RD, Tiwari GN. Thermal heating of controlled environment greenhouse: a transient analysis. Energy conversion and management. 2000; 41(5):505-522.

7. Chauhan DS. Vegetable production in India (Hindi translation), G.B. Pant University of Agril \& technology. Pant Nagar U.P., India, 1976.

8. Nelson PV. Greenhouse operation and maintenance P 340, Ruston Publ. Co., Virginia USA, 1985.

9. Bakker JC. Effects of day and night humidities on yield and fruit quality of greenhouse tomatos. J. Hort. Sci. 1990; 65:323- 331.

10. Alhamdan AM, Al-Helal IM. Mechanical deterioration of polyethylene greenhouses covering under arid conditions. Journal of Materials Processing Technology. 2009; 209(1):63-69.

11. Shamshiri R, Ismail WIW, Ahmad D. Experimental evaluation of air temperature, relative humidity and vapor pressure deficit in tropical lowland plant production environments. Advances in Environmental Biology, 2014; 8(22):5-13.

12. Zhang Z, Gates RS, Zou ZR, Hu XH. Evaluation of ventilation performance and energy efficiency of greenhouse fans. Int J Agric \& Biol Eng, 2015; 8(1):103110.

13. Jain D, Tiwari GN. Modeling and optimal design of evaporative cooling system in controlled environment greenhouse. Energy Conversion and Management. 2002; 43(16):2235-2250.

14. Sethi VP, Dubey RK, Dhath AS. Design and evaluation of modified screen net house for off-season vegetable raising in composite climate. Energy Conversion and Management. 2009; 50(12):3112-3128.

15. Montero JI, Baeza E, Heuvelink E, Rieradevall J, Muñoz P, Ercilla M. Productivity of a building-integrated roof top greenhouse in a Mediterranean climate. Agricultural Systems. 2017; 158:14-22. 